\title{
QT interval in right and left bundle-branch block
}

\author{
S. Talbot \\ From Nottingham General Hospital and Sheffield Royal Infirmary
}

The $Q T$ interval of the electrocardiogram is prolonged in right and left bundle-branch block. Since the $Q T$ interval is not prolonged outside the normal range due to myocardial disease alone, this lengthening of the $Q T$ interval is due to the conduction defect and is probably due to delayed depolarization (and thus repolarization) of the heart. There is, however, a significant difference in the $Q T$ interval in left and right bundle-branch block ( $t=3.86 ; P<0 \cdot 01)$, since the $Q T$ was shorter in right than in left bundle-branch block. This may be due to the completion of normal repolarization in the left ventricle, so that only in some cases of right bundlebranch block does repolarization end in the right ventricle.

Correction of the actual QTc for the conduction defect of left bundle-branch block can be made by subtracting the prolongation of the $Q R S$ due to the block from the actual QTc. This will allow the QTC (corrected for conduction defect and rate) to be directly compared with normal ( $0.42 \mathrm{sec})$. Correction for right bundlebranch block can be made by subtracting $0 \cdot 20$ sec less from the actual QTc.

The QT interval is prolonged in hypokalaemia and hypocalcaemia, and shortened in hypercalcaemia. It is used to evaluate such abnormalities (Grant, 1970) and may also reflect cellular levels of these electrolytes.

However, in the presence of bundle-branch block the QT is abnormal, and it is thought such conduction defects invalidate measurements of the QT (Ashman, 1942). The QT interval decreases with increasing heart rate, and to allow for this factor a number of formulae have been proposed to express the relation between the cardiac cycle length and the QT (Bazett, 1918-1920; Ashman, 1942). These cumbersome formulae for the average and maximum normal QT have been superseded by the QTc as proposed by Kissin, Schwarzschild, and Bakst (1948). Though there are differences in men, women, and children for the QT, such differences can be ignored if the maximum figure for the normal QT is used to evaluate any individual QT.

This study was undertaken (while taking these factors into consideration) to determine the effect of bundle-branch block on the QT and to try to see if this effect of bundle-branch block could be corrected for in any measurement of the QT or QTc. This would then allow electrolyte abnormalities to be assessed even in patients with bundle-branch block.

\section{Subjects and method}

One hundred and fifty electrocardiograms showing left

Received 25 August, 1972. bundle-branch block, and 126 electrocardiograms indicating right bundle-branch block were examined during a 9-month period at two busy general hospitals. They were obtained by examination of all electrocardiograms with a QRS >0.12 sec. The criteria used in selecting cases of bundle-branch block were those of Lipman and Massie (1965). Thus the QRS was at least 0.14 sec; there was delayed onset of intrinsicoid deflection over the affected ventricle $(>0.06 \mathrm{sec}$ ) with the initial $0.04 \mathrm{sec}$ shown as a positive deflection in leads over the unaffected ventricle and the terminal $0.04 \mathrm{sec}$ shown as a negative deflection in these leads.

In 55 electrocardiograms with left bundle-branch block and 33 electrocardiograms with right bundlebranch block there were electrocardiographic changes which were not due to bundle-branch block, such as those of myocardial infarction or arrhythmias such as atrial fibrillation; in some, drugs known to affect the QT had been given or the heart rates were in excess of I50/minute or below 40/minute. These cases were excluded because of the possible effect of such factors on the QT and the difficulty of determining the QT at the extremes of heart rate (Lepeschkin, 1955). To eliminate any error due to age or sex these details were recorded for each patient.

The cycle length (C), the QT, the QRS, and the PR interval were measured for each electrocardiogram to an accuracy of $\pm 0.02 \mathrm{sec}$. All the leads were examined and the mean of the longest and shortest measurements of the QT in these leads and the longest measurement of the QRS in any lead were recorded (Grant, I970); the PR was measured in the same lead as the QRS. The ST interval (the measurement from the end of the $S$ wave to the end of the $T$ wave) was calculated from the differ- 
ence between the width of the QRS and the QT for each electrocardiogram. The significance of the differences in the average measurements of the QT in left and right bundle-branch block was determined using Student's t test.

The average QT for each bundle-branch block was compared with the average QT for normal men and women and patients with cardiac disease as determined by Ashman (1942). The constant $\mathrm{K}$ for Bazett's formula, the average $Q T=K \sqrt{C}$, was calculated for all cases of both left and right bundle-branch block and from this the QTc was determined. (Kissin et al. (1948) used the constant from Bazett's formula for the maximum QT to give the maximum QTc and found it was 0.42 : figures above this were abnormal.) From these measurements a correction factor was found that, when subtracted from the actual QTc, gave the QTC (corrected for heart rate and conduction defect).

\section{Results}

There were 43 women and 52 men with left bundlebranch block and 39 women and 54 men with right bundle-branch block. There was no significant difference in the mean age of both groups. In the Table are the measurements of the QT, the cycle length (C), the PR interval, and the QRS, and the calculated figure for the ST interval for these electrocardiograms.

TABLE Average measurements of electrocardiograms in cases of right and left bundle-branch block

\begin{tabular}{|c|c|c|}
\hline & $\begin{array}{l}\text { Right bundle- } \\
\text { branch block }\end{array}$ & $\begin{array}{l}\text { Left bundle- } \\
\text { branch block }\end{array}$ \\
\hline Mean QT & $0.395(\mathrm{SD} 0.050)$ & $0.422(S D 0.48)$ \\
\hline Mean QRS & 0.15 (SD 0.049) & 0.158 (SD 0.047) \\
\hline Mean PR & $0.171(S D 0.045)$ & $0.16 I(S D 0.046)$ \\
\hline Mean ST & 0.245 (SD 0.049) & 0.264 (SD 0.046) \\
\hline Mean C & 0.734 (SD 0.16I) & 0.737 (SD 0.163) \\
\hline $\begin{array}{l}\text { Mean age }(y r) \text { of } \\
\text { women }\end{array}$ & $70.6(\mathrm{SD}$ I2.7) & $(\mathrm{SD} / 2 \cdot 3)$ \\
\hline Mean age (yr) of men & $65 \cdot 2\left(S D_{12} \cdot 8\right)$ & $65.9\left(\operatorname{SD}_{9 \cdot 1}\right)$ \\
\hline
\end{tabular}

The normal QT for such heart rates (average $\mathrm{C}=0.735$ ) is $0.36 \mathrm{sec}$ (Ashman and Hull, 194I); the upper limit of normal is $0.38 \mathrm{sec}$. The difference of the mean QT of right bundle-branch block from normal was $0.035 \sec (t=6.54, P<0.01)$. There was a difference of $0.062 \mathrm{sec}$ between the QT of left bundle-branch block and the normal QT $(t=I 2 \cdot I$, $P<0.01$ ). Since the normal $Q R S$ width varies from 0.08 to $0.10 \mathrm{sec}$, the QRS in cases of left bundlebranch block was approximately $0.07 \mathrm{sec}$ longer than normal, and in cases of right bundle-branch block was approximately 0.06 sec longer than normal. Thus in cases of left bundle-branch block the prolongation of the QT was compatible with the increase in the width of the QRS, but was $0.03 \mathrm{sec}$ less for cases of right bundle-branch block.

There was a significant difference in the QT between left and right bundle-branch block of $0.027 \mathrm{sec}$ $(t=3.86, P<0.01)$. Little of this difference was due to a difference in the width of the QRS since the ST interval was also significantly different between the two groups $(t=2 \cdot 17, P<0.02)$.

Either the logarithmic relation, QT $=\mathrm{K} \log$ ro $(\mathrm{C}+0.07)$ as devised by Ashman (1942) or a square root relation adequately expressed the variation in the QT with heart rate. Thus for left bundle-branch block the correlation coefficient for the equation $\mathrm{QT}=\mathrm{K}(\log$ Io $(\mathrm{C}+\mathrm{R})$ ) was 0.62 and a similar coefficient for right bundle-branch block was 0.66 , $\mathrm{K}$ being 0.47 and 0.44 , respectively $(R=0.07$ as in the similar equation of Ashman, I942).

Using Bazett's formula:

$$
\begin{aligned}
& \angle B B B: \mathrm{QT}=0.488 \sqrt{\mathrm{C}} \\
& \text { The mean } \mathrm{QTc}=0.488(\mathrm{SD} 0.50) . \\
& R B B B: \mathrm{QT}=0.46 \sqrt{\mathrm{C}} \\
& \text { The mean } \mathrm{QTc}=0.46(\mathrm{SD} 0.46) .
\end{aligned}
$$

In 2 cases of left bundle-branch block the QTc was measured before and after the onset of left bundle-branch block. In a man of 60 years the QTc was measured before and after the change from right to left bundle-branch block (QTc $=0.46$ and 0.52 , respectively). In a woman of 69 years the QTc lengthened from 0.38 to 0.44 after the onset of left bundle-branch block.

No other differences were found and the slightly longer QRS in left bundle-branch block was almost exactly compensated by a decrease of the PR interval when compared to right bundle-branch block. Variation of the QT in different leads was found to be $\leqslant 0.04$ sec.

\section{Discussion}

There is a significant increase in the QT interval in patients with right and left bundle-branch block, but it is greater for left than for right bundle-branch block. In view of the frequency of myocardial diseases such as ischaemic heart disease in patients with left bundle-branch block (Hiss and Lamb, 1962) and to a lesser extent patients with right bundle-branch block (Reusch and Vivas, 1959) it could be suggested that the prolongation of the QT was secondary to this. However, though the average QT is slightly increased in patients with cardiac disease, this is within the limits of normal. Thus Ashman (1942) found that the mean QT for such patients was $0.4 \mathrm{I} \log 10(\mathrm{C}+0.07)$. Therefore, the expected QT for the right bundle-branch group would be $0.37 \mathrm{I}$ and for the left bundle-branch group 
would be $0.372 \mathrm{sec}$. This was confirmed by examination of 342 electrocardiograms of patients with cardiac disease with a QRS <0.12 sec; the mean QT was 0.364 and the average cycle length was $0.75 \mathrm{sec}$ (personal communication). Ashman (1942) found the upper limit of normal of the QT was $0.42 \log$ Io $(\mathrm{C}+0.07)$ and there is therefore no need to apply a correction factor for the QT or the QTc in patients with cardiac disease when these measurements are used to estimate electrolyte imbalance.

Although the slightly shorter QRS of the right bundle-branch block cases cannot be the cause of the shorter QT in such cases compared with left bundle-branch block, intrinsicoid deflection which represents the time of depolarization of the majority of the ventricle over which the lead is placed, occurs later in the left than the right ventricle. Intrinsicoid deflection occurs 0.015 to $0.035 \mathrm{sec}$ after the onset of the QRS in lead VI and 0.035 to $0.055 \mathrm{sec}$ after the onset in lead V6 (Lipman and Massie, 1965). This difference of $0.02 \mathrm{sec}$ is not the explanation of the difference in the QT because in 35 patients with left bundle-branch block and 24 patients with right bundle-branch block measurements of the time from intrinsicoid deflection to the end of the $T$ wave in leads V6 and VI, respectively, showed that there was a difference of $0.028 \mathrm{sec}$ between left and right bundle-branch block. The groups were comparable as regards heart rate, age, and sex and these factors could not be the cause of the difference in the QT.

There are rare cardiac diseases with prolongation of the QT (Gale et al., 1970), but it seems that usually conduction must be delayed to a large ventricular area before the QT is prolonged. Since the left ventricle makes the major contribution to the QRS (depolarization) and to repolarization (Goldman, 1970) and the latter includes all the changes up to the end of the $T$ wave, the terminal part of the $\mathrm{T}$ wave is of left ventricular origin. (Durrer et al. (1970) found that the conus of the right ventricle and the posterobasal segments of the heart were excited last (after 60-70 msec); they admitted that these areas might not contribute significantly to the QRS. Similar considerations probably apply to repolarization.) Therefore probably the delay in repolarization of the right ventricle in right bundlebranch block in most cases is not of sufficient magnitude to delay the termination of the $T$ wave.

It seems necessary to estimate a correction factor for the QT in bundle-branch block even if the block is not associated with other evidence of cardiac disease. Since it is impossible to exclude myocardial disease in patients with bundle-branch block, or to be certain of the anatomical site of the blocks, these correction factors apply to an electrocardiographic diagnosis.
As would be expected from the previous equation, the prolongation of the QT in patients with bundlebranch block is greater at slower heart rates. However within the limits of heart rate of this study, a simple correction can be made by subtraction of $0.06 \mathrm{sec}$ from the QT of patients with left bundle-branch block and $0.03 \mathrm{sec}$ from the QT of patients with right bundle-branch block. In view of the slight variation in the width of the QRS, this can also be taken into consideration. Thus the correction factor in patients with left bundle-branch block is found by subtraction of $0.10 \mathrm{sec}$ from the width of the QRS and similarly by subtraction of $0.12 \mathrm{sec}$ from the width of the QRS in patients with right bundle-branch block.

The QTc is of greater use in cardiology, and by subtraction of $0.07 \mathrm{sec}$ in cases of left bundle-branch block, and of $0.04 \mathrm{sec}$ in right bundle-branch block from the calculated QTc for each case, comparison with the maximum normal QTc $(0.42)$ can be made. Such calculations will be helpful when the electrocardiogram is being used to assess hypokalaemia or hypocalcaemia since lengthening of the QT (or QTc) is a valuable sign of such conditions (Lipman and Massie, 1965).

However, Lepeschkin (1955) considered that the composite nature of the QT militated against its usefulness. It would be better divided into three parts, the QRS (depolarization), the ST segment (from the $S$ wave to the beginning of the $T$ wave, phase 2 of the action potential), and the $T$ wave (phase 3 of the action potential). Certainly the ST interval as measured here from the end of the QRS to the end of the $T$ wave is more useful than the QT and has a similar relation to the heart rate.

I am grateful for the advice of Dr. J. S. Fleming and the help of cardiology technicians at Sheffield Royal Infirmary and Nottingham General Hospital.

\section{References}

Ashman, R. (1942). The normal duration of the QT interval. American Heart fournal, $23,522$.

Ashman, R., and Hull, E. (I94I). The Essentials of Electrocardiography, 2nd ed. MacMillan, London.

Bazett, H. C. (1918-1920). An analysis of the time-relations of the electrocardiograms. Heart, 7, 353.

Durrer, D., Van Dam, R. Th., Freud, G. E., Janse, M. J., Meyler, F. L., and Arzbaecher, R. C. (1970). Total excitation of the isolated human heart. Circulation, 41, 899.

Gale, G. E., Bosman, C. K., Tucker, R. B. K., and Barlow, J. B. (1970). Hereditary prolongation of QT interval; study of two families. British Heart fournal, 32, 505.

Goldman, M. J. (1970). Principles of Clinical Electrocardiography, 7th ed. Lange Medical, Los Altos, California.

Grant, R. P. (1970). Clinical Electrocardiography. McGraw Hill, New York.

Hiss, R. G., and Lamb, L. E. (1962). Electrocardiographic findings in 122,043 individuals. Circulation, 25, 947. 
Kissin, M., Schwarzschild, M. M., and Bakst, H. (1948). A nomogram for rate correction of the QT interval in the electrocardiogram. American Heart fournal, 35, 990.

Lepeschkin, E. (1955). The U wave of the electrocardiogram. Archives of Internal Medicine, 96, 600.

Lipman, B. S., and Massie, E. (1965). Clinical Scalar Electrocardiography, 5th ed. Year Book Medical Publishers, Chicago.
Reusch, C. S., and Vivas, J. R. (1959). Clinical analysis of right bundle branch block. American Heart fournal, 58, 543.

Requesty for reprints to Dr. S. Talbot, Sheffield Royal Infirmary, Sheffield. 
without a praecordial vibratory murmur. Also, as already mentioned, blood pressure readings between the two groups did not differ significantly. This means that no difference in windkessel-function of the aorta can be assumed in explaining the presence of a praecordial vibratory murmur, which leaves left ventricular myocardial function as the most probable basic origin.

\section{References}

Beneken, J. E. W., and de Wit, B. (I967). A physical approach to hemodynamic aspects of the human cardiovascular system. In Physical Basis of Circulatory Transport: Regulation and Exchange, p. 7. Ed. by E. B. Reeve and A. C. Guyton. Saunders, Philadelphia.

Bruns, D. L. (1959). A general theory of the causes of murmurs in the cardiovascular system. American fournal of Medicine, 27, 360.

de Monchy, C. (I966a). Studies on functional heart murmurs in children. I. The external carotid tracing of children with a precordial vibratory murmur. Annales Paediatrici, 206, 356.

de Monchy, C. (1966b). Studies on functional heart murmurs in children. II. The origin of the precordial vibratory murmur and the pulmonic systolic murmur in children. Annales Paediatrici, 206, 408.

Harris, T. N., and Friedman, S. (1952). Phonocardiographic differentiation of vibratory (functional) murmurs from those of valvular insufficiency; further observations and application to the diagnosis of rheumatic heart disease. American Heart fournal, 43, 707.

McConahay, D. R., Martin, C. M., and Cheitlin, M. D.
(1972). Resting and exercise systolic intervals. Correlations with ventricular performance in patients with coronary artery disease. Circulation, 45, 592.

McKusick, V. A. (1958). Cardiovascular Sound in Health and Disease. William and Wilkins, Baltimore.

Montoye, H. J., Willis, P. W., Howard, G. E., and Keller, J. B. (1970). Systolic pre-ejection period. Archives of Environmental Health, 21, 425.

Paulin, S., and Mannheimer, E. (1957). The physiological heart murmur in children. Acta Paediatrica, 46, 438.

Robinson, B. (1963). The carotid pulse. I. Diagnosis of aortic stenosis by external recordings. British Heart fournal, 25, 51.

Rushmer, R. F. (1955). Cardiac Diagnosis. Saunders, Philadelphia.

Snedecor, G. W. (1967). Statistical Methods, 6th ed. Iowa State College Press, Ames, Iowa.

van der Hoeven, G. M. A., de Monchy, C., and Beneken, J. E. W. (1973). Studies on innocent praecordial vibratory murmurs in children. I: Systolic time intervals and pulsewave transmission times in normal children. British Heart Fournal, 35, 669 .

van der Hoeven, G. M. A. (1970). De analoge rekenmachine, een hulpwerktuig bij de bestudering van de bloedsomloop. Polytechnisch Tijdschrift, E, 25, No. 12, 472.

Weissler, A. M., Harris, W. S., and Schoenfeld, C. D. (1969). Bedside technics for the evaluation of ventricular function in man. American fournal of Cardiology, 23, 577.

Wennevold, A. (1967). The origin of the innocent 'vibratory' murmur studied with intracardiac phonocardiography. Acta Medica Scandinavica, 18I (I), I.

Requests for reprints to Dr. C de Monchy, c/o Institute of Medical Physics, T.N.O., Da Costakade 45, Utrecht, The Netherlands.

\section{Errata}

' $Q T$ interval in right and left bundle-branch block' by $\mathrm{S}$. Talbot, volume 35, p. 288 and 289.

(i) The last line of the summary should read 'by subtracting $0.02 \mathrm{sec}$ less from the actual QTc'

(ii) First row, second column of the Table (mean QT in left bundle-branch block) should be 0.422 (SD 0.048). 